\title{
Long-term trends in fertility of soils under continuous cultivation and cereal cropping in southern Queensland. IX*. Simulation of soil carbon and nitrogen pools using CENTURY model
}

\author{
C. R. Chilcott ${ }^{\mathrm{A}, \mathrm{B}, \mathrm{E}}$, R. C. Dalal ${ }^{\mathrm{B}}$, W. J. Parton ${ }^{\mathrm{C}}$, J. O. Carter ${ }^{\mathrm{B}}$, and A. J. King ${ }^{\mathrm{D}}$ \\ ${ }^{\text {A } Q u e e n s l a n d ~ D e p a r t m e n t ~ o f ~ P r i m a r y ~ I n d u s t r i e s ~ a n d ~ F i s h e r i e s, ~} 665$ Fairfield Road, Yeerongpilly, \\ Qld 4105, Australia. \\ ${ }^{B}$ Queensland Department of Natural Resource, Mines and Water, 80 Meiers Road, Indooropilly, \\ Qld 4068, Australia. \\ CNatural Resource Ecology Laboratory, Colorado State University, Fort Collins, CO, USA. \\ DQueensland Department of Natural Resource, Mines and Water, 203 Tor Street, Toowoomba, \\ Qld 4350, Australia. \\ ECorresponding author. Email: Chris.Chilcott@dpi.qld.gov.au
}

\begin{abstract}
Cultivation and cropping of soils results in a decline in soil organic carbon and soil nitrogen, and can lead to reduced crop yields. The CENTURY model was used to simulate the effects of continuous cultivation and cereal cropping on total soil organic matter $(\mathrm{C}$ and $\mathrm{N})$, carbon pools, nitrogen mineralisation, and crop yield from 6 locations in southern Queensland. The model was calibrated for each replicate from the original datasets, allowing comparisons for each replicate rather than site averages. The CENTURY model was able to satisfactorily predict the impact of long-term cultivation and cereal cropping on total organic carbon, but was less successful in simulating the different fractions and nitrogen mineralisation. The model firstly over-predicted the initial (pre-cropping) soil carbon and nitrogen concentration of the sites. To account for the unique shrinking and swelling characteristics of the Vertosol soils, the default annual decomposition rates of the slow and passive carbon pools were doubled, and then the model accurately predicted initial conditions. The ability of the model to predict carbon pool fractions varied, demonstrating the difficulty inherent in predicting the size of these conceptual pools. The strength of the model lies in the ability to closely predict the starting soil organic matter conditions, and the ability to predict the impact of clearing, cultivation, fertiliser application, and continuous cropping on total soil carbon and nitrogen.
\end{abstract}

\section{Introduction}

Maintaining or improving the soil organic matter levels in soils is critical for production sustainability in agricultural systems. Continuous cultivation and cereal cropping results in a decline in the soil organic matter (SOM) and soil nitrogen and can lead to a reduction in crop yields. Developing the capacity to predict long-term changes in SOM due to cultivation and cereal cropping has lead to the development of several simulation models. The CENTURY SOM model was initially developed using data from temperate soils to simulate SOM dynamics in temperate grassland soils in the North American Great Plains (Parton et al. 1987). Since then it has been used in various regions, including southern Australia (Carter et al. 1993), tropical soils and forests (Parton et al. 1989; Sanford et al. 1991), as well as subtropical and tropical agroecosystems (Paustian et al. 1992; Woomer 1993; Parton et al. 1994a, 1994b) and in the comparison of long-term experiments (Smith et al. 1997), all with considerable success.

\footnotetext{
*Part VIII, Aust J. Soil. Res., 1990 pp. 563-575.
}

The CENTURY model is based on several conceptual pools of SOM-metabolic and structural litter pools, active, slow, and passive SOM pools. Soil texture regulates the transfer of $\mathrm{C}$ between the SOM pools. The formation and persistence of the passive SOM pool is assumed to be a function of soil clay content (Parton et al. 1987). Indeed, Dalal and Mayer (1986b) observed that the rate of loss of SOM was inversely related to the clay content of the soils studied, as the clay provided protection against microbial and enzyme degradation in their studies on the decline in SOM following clearing of native vegetation and cultivation.

Dalal and Mayer (1986a, 1986b, 1986c, 1986d, 1986e, $1987 a, 1987 b)$ measured the SOM (C and N) dynamics and its pools (microbial, clay-size SOM, silt size SOM, and sand-size SOM), total nitrogen, and crop yield in their studies on the longterm impacts of continuous cultivation and cereal cropping at 6 locations across southern Queensland. The observation dataset used is unique in the detailed measurements of pools sizes, nitrogen mineralisation, and cropping and cultivation history, thus allowing us to simulate each replicate from each separately. Since the CENTURY model is based on various conceptual pools of SOM, these data provide the opportunity to test the 
model's ability to predict the impacts of long-term cultivation and continuous cereal cropping on total soil SOM $(\mathrm{C}$ and $\mathrm{N})$ and the pools of SOM. The objective of this study was to simulate the impact of long-term continuous cultivation and cereal cropping on total SOM (C and N), carbon pools, nitrogen mineralisation, and crop yields using the CENTURY model, and compare the simulations against measured data reported by Dalal and Mayer (1986a, 1986b, 1986c, 1986d, 1986e, 1987a, 1987b, 1990).

\section{Materials and methods}

\section{Model description}

The simulations were preformed with the CENTURY model (Version 4.0), which has been described in detail by Parton et al. (1992) and Metherell et al. (1993). The CENTURY model simulates $\mathrm{C}$ and $\mathrm{N}$ (and $\mathrm{P}$ and $\mathrm{S}$ ) dynamics in soil-plant systems for different ecosystems (grasslands, forests, crops, and savannas). The model has 5 pools of SOM, 2 representing aboveground plant residue and 3 representing SOM. The 3 major components of SOM include: $(a)$ the active pool, consisting of live soil microbial biomass, microbial biomass associated with decomposing surface plant material, and microbial products with the most rapid turnover rate; $(b)$ the slow pool, consisting of resistant plant material (mostly lignin derived) and soil stabilised plant and microbial decomposition products with an intermediate turnover rate; and $(c)$ the passive pool, consisting of physically and chemically stabilised SOM with the slowest turnover rate. Carbon flows between pools vary with monthly precipitation and temperature and soil texture. Soil texture regulates the rate of transfer between slow and passive pools with higher turnover rates for sandy soils but higher stabilisation rates for clay soils.

\section{Simulating the experiments and parameterisation}

Each treatment in the experimental observation was simulated separately, allowing comparisons for each replicate (rather than site averages) from the original data. Management histories, and clearing and cropping times and intensities were available for each site, and these were used as to develop simulation schedule files for each replicate. Simulations were run from year 0 to 1850 (when specific management schedules commenced) to equilibrate the initial SOM levels and pools distribution, since direct determination of initial pool sizes is problematic (Paustian et al. 1992) because these are conceptual pools in the CENTURY model rather than experimentally determined fractions. Control sites were used to calibrate the initial input parameters. In this study, we assumed that initial SOM contents were at steadystate and the relative size of each SOM pool was estimated from the turnover rates and yield coefficients and adjusted for sitespecific factors (e.g. soil texture), similar to the approach taken by Parton et al. (1987) and Paustian et al. (1992). Sites were run with the pre-clearing vegetation types (Table 1), with production potential, biomass pools, and proportional allocation, $\mathrm{C}: \mathrm{N}$ ratios and lignin content for Eucalyptus were derived from Harrington (1979) and Judd et al. (1996) and Acacia harpophylla from Moore et al. (1967). The grass layer was run with a general subtropical pasture parameters derived from Day et al. (1997).

All replicates had the same pre-1850 land-use schedule, with no grazing and a hot fire every 4 years. However, post-1850 moderate grazing by domestic stock was introduced, with fire every 6 years at moderate intensity. This land-use schedule was run until the initial clearing and/or cultivation in preparation for cropping occurred on the replicate. In some instances, clearing of the tree layer occurred many years before the first cultivation and cropping event. In these instances, the general subtropical pasture was grown following the clearing, and grazing continued at a high level with fire excluded until cultivation and cereal cropping occurred. The general management practice was that clearing removed all live trees from the sites with the residue heaped and burnt on site, represented in the model by killing all root pools to eliminate regrowth and not allowing any return of $\mathrm{N}$ or $\mathrm{C}$ to the soil or surface layers.

Grazing effects are defined in terms of the amount of material removed in the grazing event, and the fraction that is subsequently excreted through urine and faeces. Grazing affects subsequent plant production through removing vegetation, returning nutrients to the soil, changes root: shoot ratios, and increasing $\mathrm{N}$ content of live roots and shoots (Holland et al. 1992), with the option for either a linear or quadratic effect. The moderate grazing level was set to remove $10 \%$ of total live shoots with a grazing event and $1 \%$ of standing dead material, and had a linear decrease in potential plant production with increasing grazing intensity. The high grazing level removed $30 \%$ of total live shoots and $15 \%$ of standing dead material, with a quadratic impact on aboveground production and root: shoot ratio. The return of $\mathrm{C}$ through animal excretion was set at $30 \%$ of both grazing intensities, with $90 \%$ of $\mathrm{N}$ returned in the moderate grazing and $80 \%$ in the heavy grazing. Fire effects are also derived from Holland et al. (1992), causing increases in root: shoot ratio, increased $\mathrm{C}: \mathrm{N}$ ratio of shoots and roots, and removal of vegetation and return nutrients. The moderate fire used in the simulations removed $70 \%$ of the standing dead and live shoot materials in the grass layer and $30 \%$ of the surface litter, and allowed $20 \%$ of the $\mathrm{N}$ to return to the soil.

Information on the total amount of fertiliser applied to the replicate was available but not the year and frequency of application. The maximum amount of fertiliser added per annum was limited to $30 \mathrm{~kg} \mathrm{~N} / \mathrm{ha}$, applied once in the month of crop planting (Dalal and Mayer 1986a). The number of fertiliser years was scheduled to accumulate to the total amount applied per site by the end of the simulation.

The number of cultivation passes per crop was 3-6, depending on the total observed for the replicate. Prior to 1967, the tillage system used was convention disc cultivators, with chisel ploughs used in the remainder of years of the simulation. The model defines cultivation in terms of the intensity of disturbance leading to an increase in decomposition rates of organic matter pools, and the degree of mixing of aboveground plant materials into the soil and soil surface. Conventional cultivation was set to transfer at least $90 \%$ of stubble matter (standing dead and surface litter) into the surface litter or topsoil layers, while the chisel plough returned $35 \%$ of stubble matter (Littleboy et al. 1989) into the surface litter pool, and $70 \%$ of the surface litter into the topsoil layer. The multiplicative effect of soil disturbance on decay rates in the month of cultivation, applied to all the SOM pools, was 1.6 and 1.3 for the conventional disc cultivator and chisel plough, respectively. 


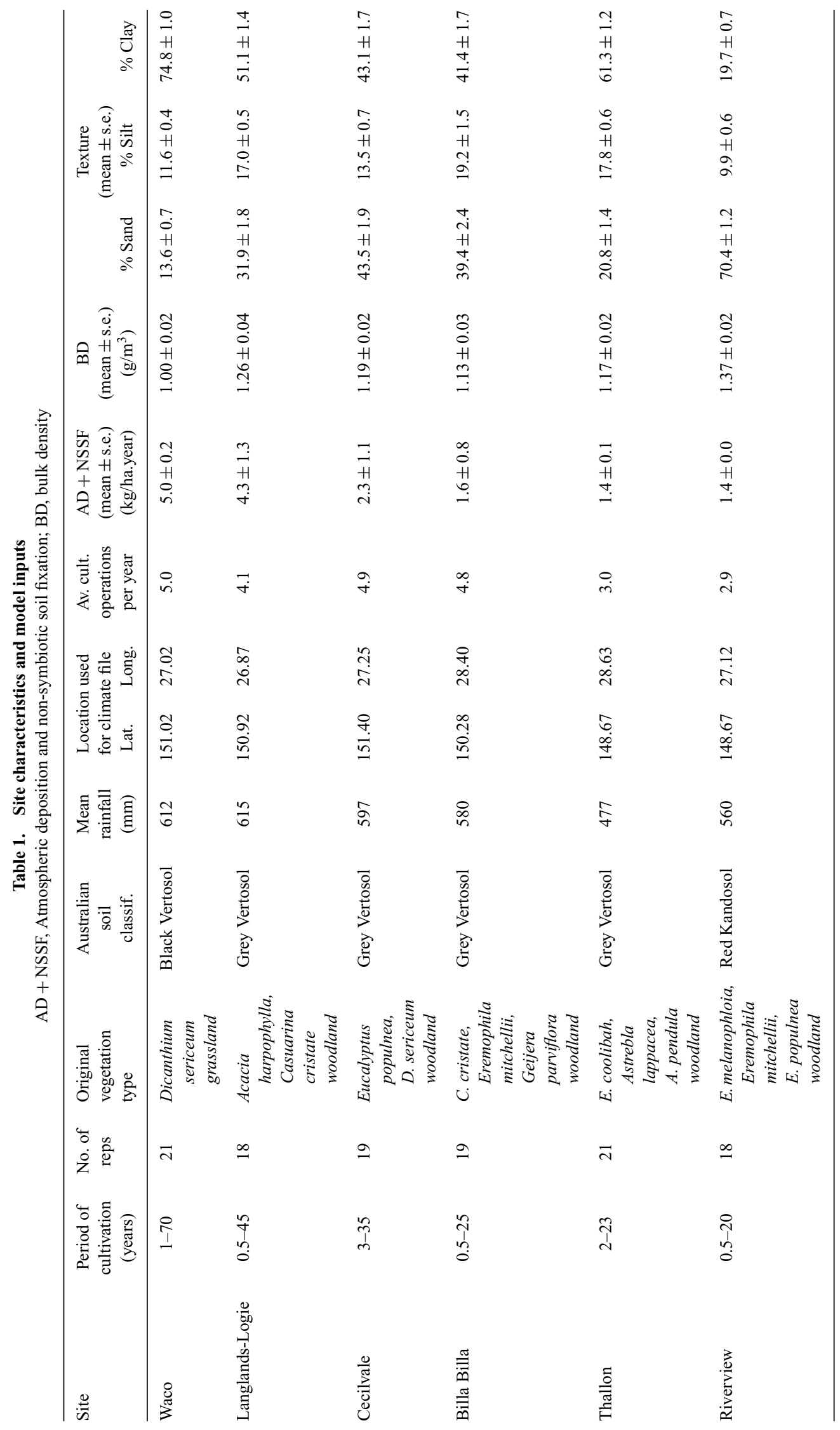


Monthly precipitation and monthly average maximum and minimum air temperatures were obtained from the SILO national interpolated climate surfaces (Jeffrey et al. 2001) using the latitude and longitude for each location. A range of $1.3-6.7 \mathrm{~kg}$ $\mathrm{N} /$ ha.year was contributed to the replicate via atmospheric deposition and soil and plant $\mathrm{N}_{2}$ fixation, varying as a linear function of annual precipitation (Metherell et al. 1993) across the sites (the most with the highest rainfall, Table 1). Soil texture and bulk density were available for each replicate, while site average plant-available water content per $0.10-\mathrm{m}$ layer to $0.90 \mathrm{~m}$ was used for each replicate, as individual estimates were not available.

Observational data collection methods and experimental treatments are detailed in Dalal and Mayer (1986a). A summary of treatments, replicates, and site information is given in Table 1. The CENTURY simulates the SOM to a depth of $0.20 \mathrm{~m}$, and comparisons against collected data were adjusted to these depths. Given that simulations were run for 1850 years to equilibrate the initial SOM levels and pool distribution, it is possible to compare the total and pool distribution for the control and treatment plots, since Dalal and Mayer (1986c, 1987a) measured different $\mathrm{C}$ and $\mathrm{N}$ fractions, allowing comparisons of the pool distribution across all replicates and cultivations against CENTURY pool distribution (Table 2).

The accuracy of the simulation in predicting the changes to total soil organic carbon (SOC), nitrogen, SOC pools (Table 2), and grain yield was tested by comparing the observed and predicted data for all sites through a linear regression, and by comparing the coefficient of determination $\left(r^{2}\right)$ and the root mean square deviation (RMSD) of observed (O) and predicted (P) values, where:

$$
\mathrm{RMSD}=\left[\sum(\mathrm{O}-\mathrm{P})^{2} / n\right]^{0.5}
$$

Grain yields were recorded at all sites over the life of the cultivation (Dalal and Mayer 1986a). Comparisons between the site average yield (measured as grain yield per area) (Dalal and Mayer 1986a, 1990) and simulated grain yield were made, to test whether the model made reasonable predictions of crop growth and maintained a sensible steady-state return of plant $\mathrm{C}$ and $\mathrm{N}$ to the soils.

\section{Results}

\section{Initial conditions}

The model initially over-predicted the soil $\mathrm{C}$ and $\mathrm{N}$ concentrations of 4 of the 6 sites: Waco, Langlands-Logie, Billa Billa, and Thallon. The model predicted almost twice the SOC content in the uncultivated state, before the clearing of native vegetation (Fig. 1a). To account for self-mulching and swelling-shrinking characteristics of the Vertosols, the default annual decomposition rate of SOM was doubled within the slow (from 0.0045 to $0.0090 /$ year) and passive (from 0.2 to $0.4 /$ year) pools. With this correction, the model was then able to accurately predict the initial conditions before cultivation of all sites (Fig. $1 b$ ), with SOC, the coefficient of determination, $r^{2}=0.95(P<0.001, n=35)$ and $\mathrm{RMSD}=29.4 \mathrm{~kg} / \mathrm{ha}$, and total $\mathrm{N}, r^{2}=0.71(P<0.001 n=35)$ and $\mathrm{RMSD}=68.0 \mathrm{~kg} / \mathrm{ha}$. The remaining sites used the default annual decomposition rates, and the CENTURY model accurately predicted their initial conditions.

\section{Total SOC and N}

The dynamics of the total SOC for all sites are shown in Fig. $2(a-f)$. In general, the model closely predicted the effects of cultivation on total soil carbon pools, with a rapid decline in the amount of SOC in the first 10-20 years, slowly approaching a steady-state after that time. The closest fit between observed and predicted values was for Riverview, with the model able to explain $98 \%$ of the variation for SOC (Table 3). The simulations have a significant $(P<0.01$ correlation against the observed SOC at all sites, with the poorest fit at the Thallon site (explaining $69 \%$ of variation, Table 3 ). The total $\mathrm{N}$ estimates were not as accurate as those of total SOC, but were generally distributed along the $1: 1$ line, with the model explaining $61 \%$ of the variation for all sites and all ages of cultivation (Fig. 3). On a site basis, only Waco and Langlands-Logie had significant fit between observed and predicted total N (Table 3).

Table 2. Comparison of observed and predicted carbon and nitrogen pools

\begin{tabular}{|c|c|c|}
\hline Name & Observed & Simulated \\
\hline Total carbon & Total $\mathrm{C}^{\mathrm{A}}$ & $\begin{array}{l}\text { Total soil C including belowground structural and metabolic pools }{ }^{\mathrm{F}} \\
\text { SOMTC }\end{array}$ \\
\hline Microbial carbon & Microbial $\mathrm{C}^{\mathrm{B}, \mathrm{C}}$ & $\begin{array}{l}\mathrm{C} \text { in surface microbial pool }{ }^{\mathrm{F}} \\
\operatorname{SOM}(1) C(1)\end{array}$ \\
\hline Active carbon & Sand fraction ${ }^{\mathrm{B}, \mathrm{C}}$ & $\begin{array}{l}\text { Sum of the } \mathrm{C} \text { in active } \mathrm{SOM} \text {, belowground litter structural } \mathrm{C} \text { and the metabolic } \mathrm{C} \\
\text { in belowground litter } \\
\sum S O M(1) C(2), \operatorname{STRUCC}(2), \operatorname{METABC}(2)\end{array}$ \\
\hline Slow carbon & $\begin{array}{l}\text { Difference between total } \mathrm{C} \text { and microbial, } \\
\text { active, and passive pools }\end{array}$ & $\begin{array}{l}\mathrm{C} \text { in slow pool } \mathrm{SOM}^{\mathrm{F}} \\
\mathrm{SOM} 2 \mathrm{C}\end{array}$ \\
\hline Passive carbon & Clay fraction ${ }^{\mathrm{B}, \mathrm{C}}$ & $\begin{array}{l}\mathrm{C} \text { in the passive } \mathrm{SOM}^{\mathrm{F}} \\
\text { SOM } 3 C\end{array}$ \\
\hline Total nitrogen & Total $\mathrm{N}^{\mathrm{C}, \mathrm{D}}$ & $\begin{array}{l}\text { Total } \mathrm{N} \text { in soil organic matter including belowground structural and metabolic pools } \\
\text { SOMTE(1) }\end{array}$ \\
\hline Mineralised nitrogen & Cumulative $\mathrm{N}$ mineralised $^{\mathrm{E}}$ & $\begin{array}{l}\text { Annual accumulation of net } \mathrm{N} \text { mineralised from all compartments }{ }^{\mathrm{F}} \\
\operatorname{TNETMN(1)}\end{array}$ \\
\hline
\end{tabular}

${ }^{\mathrm{A}}$ Dalal and Mayer (1986b). ${ }^{\mathrm{B}}$ Dalal and Mayer (1986c). ${ }^{\mathrm{C}}$ Dalal and Mayer (1986a). ${ }^{\mathrm{D}}$ Dalal and Mayer (1986e). ${ }^{\mathrm{E}}$ Dalal and Mayer (1987b). ${ }^{\mathrm{F}}$ Parton et al. (1992). 


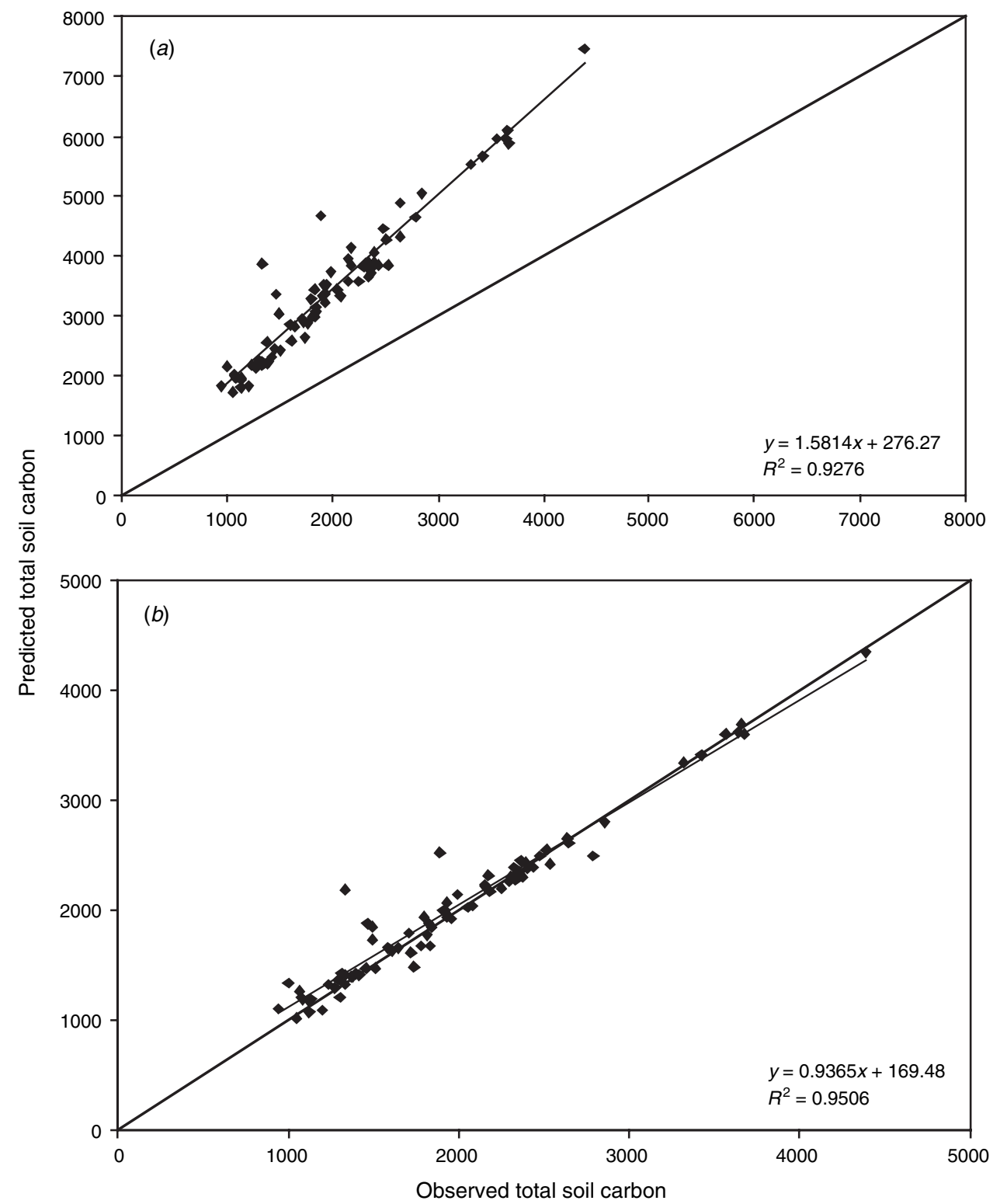

Fig. 1. Observed $v$. predicted initial condition (uncultivated) total SOC ( $\mathrm{kg} / \mathrm{ha}, 0-0.20 \mathrm{~m}$ depth) at Waco, Langlands-Logie, Billa Billa, and Thallon site $(a)$ without swelling-shrinking effect, and $(b)$ with swelling-shrinking effect correction. The solid diagonal line is the $1: 1$ line, with other line the linear regression.

\section{Carbon pool distribution}

Overall there was a good fit between the observed and predicted total SOC across all sites and all ages of cultivation (Fig. 4), with the model able to accurately predict the total soil SOC $\left(R^{2}=0.95\right)$. Comparisons of observed $v$. predicted for the individual SOC pools are given in Fig. $5(a-d)$. The ability of the model to predict changes in the carbon fractions as measured by operationally defined procedures was varied. The 2 most rapidturnover and smallest pools, the microbial and active fractions, did not have a good fit between the observed and predicted values. The CENTURY model simulated a reduction in these pools caused by the cultivation, limiting the size to $<60 \mathrm{~kg} / \mathrm{ha}$ $(0-0.20 \mathrm{~m} \mathrm{depth})$ and $600 \mathrm{~kg} / \mathrm{ha}(0-0.20 \mathrm{~m}$ depth $)$, for the microbial and active pools, respectively, even though the observed data were almost twice these values in both pools. For individual sites, the active pool was accurately predicted for Langlands-Logie, Cecilvale, and Billa Billa clays, countered by poor prediction at the other sites (Table 3 ). There was a reasonable fit with the prediction in the slow pool, with the data mostly distributed below the $1: 1$ line, indicating an underprediction. The passive pool showed not as good a fit as the slow pool, and the data tended to be above the $1: 1$ line, indicating the model tended to over-predict the pool size as defined by the procedures used. At individual sites, there was a significant fit below the predicted slow pool and the observed pool for all sites, but the best fit was for Billa Billa where the model explained $78 \%$ of the variation in the measured slow pool, whereas most other pools were not as well predicted (Table 3). 

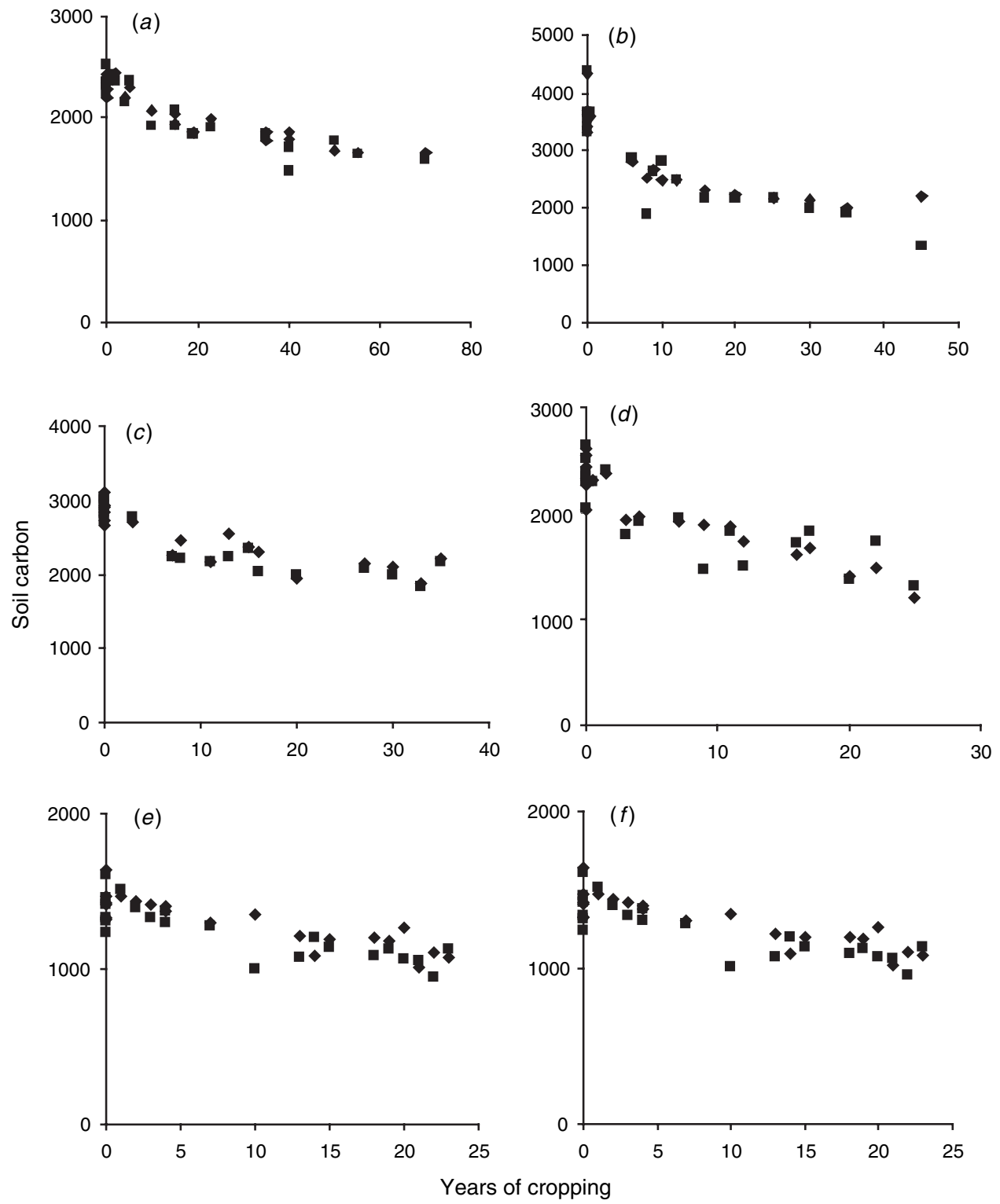

Fig. 2. Observed $(\bullet)$ and predicted (ם) total SOC ( $\mathrm{kg} / \mathrm{ha}, 0-0.20 \mathrm{~m})$ for $(a)$ Waco, $(b)$ Langlands-Logie, (c) Cecilvale, (d) Billa Billa, (e) Thallon, (f) Riverview.

\section{Mineralised nitrogen}

Observed and predicted data for the mineralised nitrogen in the $0-0.20 \mathrm{~m}$ layer are shown in Fig. 6 , with regressions for individual sites presented in Table 3. There was a poor correlation between the observed and predicted values, with the CENTURY model tending to limit the mineralised nitrogen to $<5 \mathrm{~kg} / \mathrm{ha}$, whereas the observed data ranged up to $25 \mathrm{~kg} / \mathrm{ha}$. The observed data were the maximum potential mineralised $\mathrm{N}$ collected from laboratory incubations over 30 weeks, whereas the CENTURY data were the annual accumulation of mineralised $\mathrm{N}$ within the soil profile under simulated field conditions. Thus, subsequent comparisons of the observed and predicted data may serve little purpose in evaluating the model's ability to estimate nitrogen mineralisation.

\section{Grain yield}

In spite of poor prediction of mineralisable $\mathrm{N}$, there was a reasonably good estimate of the grain yield across all sites (Table 3; Fig. 7a) except for Thallon, where yields were underestimated by CENTURY. The model fit was improved by removing the Thallon grain yield data $\left(r^{2}=0.85\right.$ $(P<0.001, n=70)$ and $\mathrm{RMSD}=63.5 \mathrm{~kg} / \mathrm{ha})($ Fig. $7 b)$. The model was able to reasonably predict the wheat yield across the range of different replicates, number of cultivations, and the variety of crop management. In the simulations, we used a generic wheat growth model parameterised to represent wheat varieties used in southern Queensland, although the varieties varied across the sites depending on the age of cultivation. 


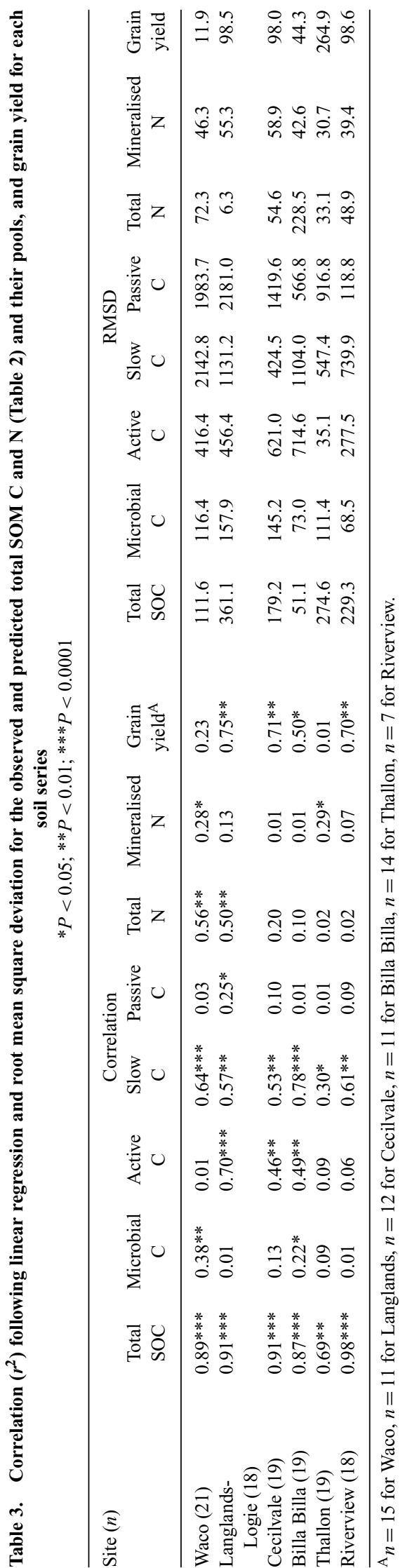




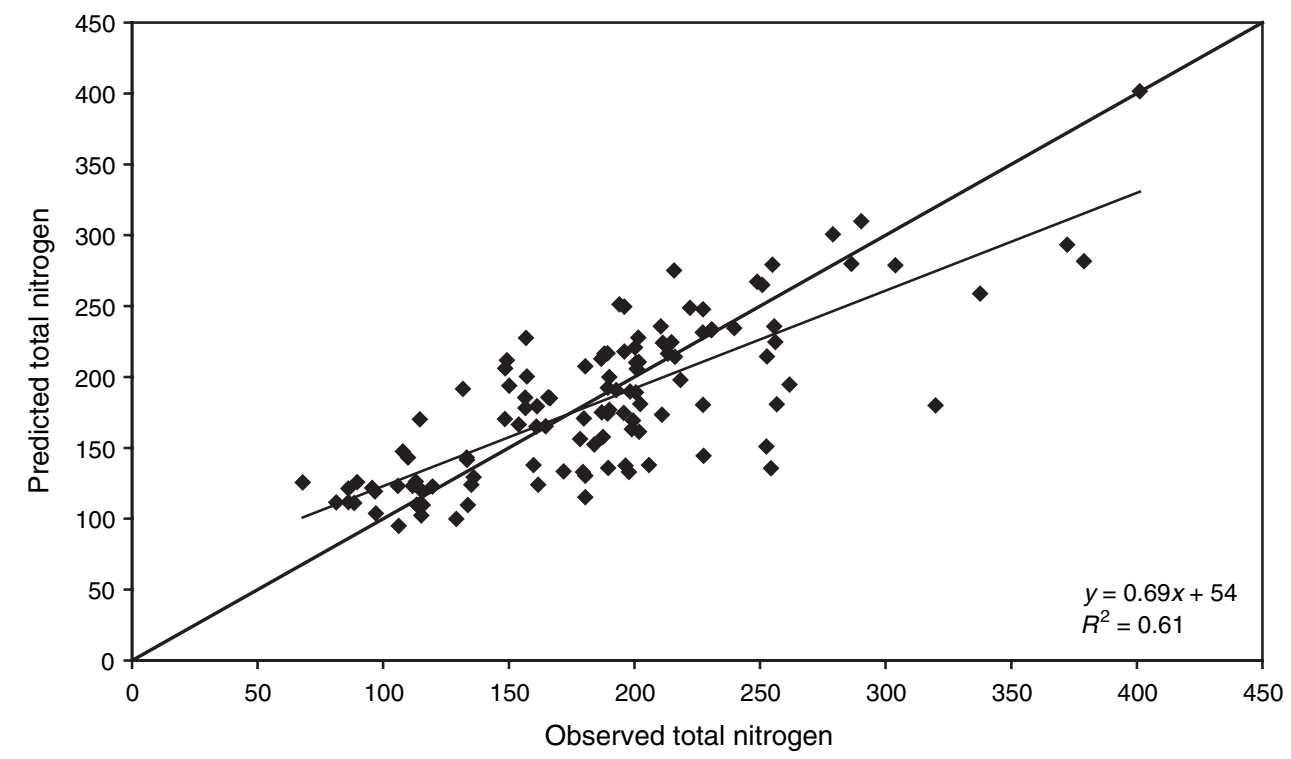

Fig. 3. Observed $v$. predicted total SOM nitrogen $(\mathrm{kg} / \mathrm{ha}, 0-0.20 \mathrm{~m}$ depth) for all sites and ages of cultivation. The solid line is the $1: 1$ line, with other line the linear regression.

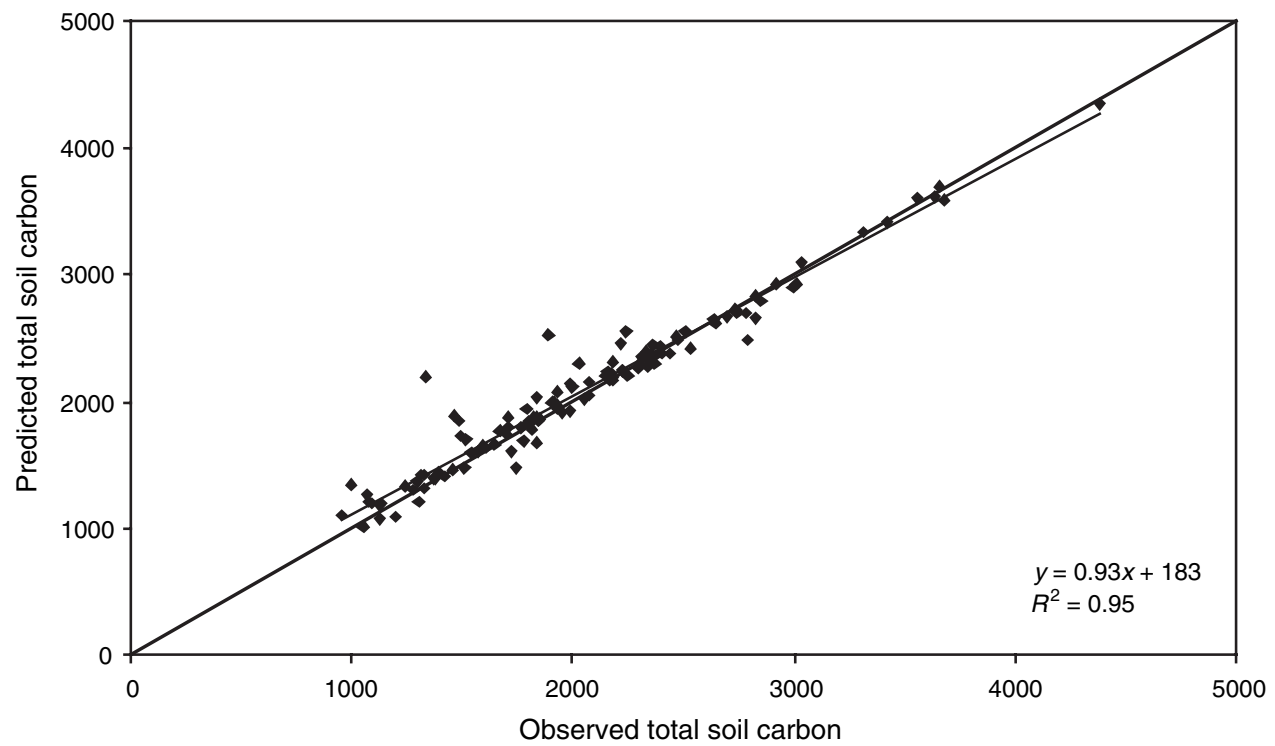

Fig. 4. Observed $v$. predicted total SOC ( $\mathrm{kg} / \mathrm{ha}, 0-0.20 \mathrm{~m}$ depth) for all sites and ages of cultivation. The solid line is the $1: 1$ line, with other line the linear regression.

\section{Discussion}

The CENTURY model was able to satisfactorily predict the impact of long-term cultivation and cereal cropping on the total soil SOC, and to a lesser extent it predicted the effects on different carbon fractions and nitrogen. The ability to do this was enhanced by establishing the initial conditions of the soils before the removal of native vegetation and the imposition of the cultivation and fertiliser regimes observed at the sites. The soils of the study sites were mostly Vertosols, unique in that most of these soils are self-mulching, and these soils shrink and swell considerably on drying and wetting. To this extent, a significant pedoturbation occurs, resulting in soil carbon and nitrogen turnover rates in excess of non-Vertosol soils with similar clay contents. To account for the shrink-swell properties, the CENTURY model was calibrated to account for this unique characteristic of Vertosols. Consequently, the annual decomposition rate of the slow and passive pools was doubled. With this correction in place, the initial conditions (i.e. the sites before clearing and cultivation) were very closely predicted by the CENTURY model. These swelling-shrinking clay soils are thus an exception to the widely observed relationship between organic $\mathrm{C}$ and clay content (Parton et al. 1994a), and if based on texture alone, the 

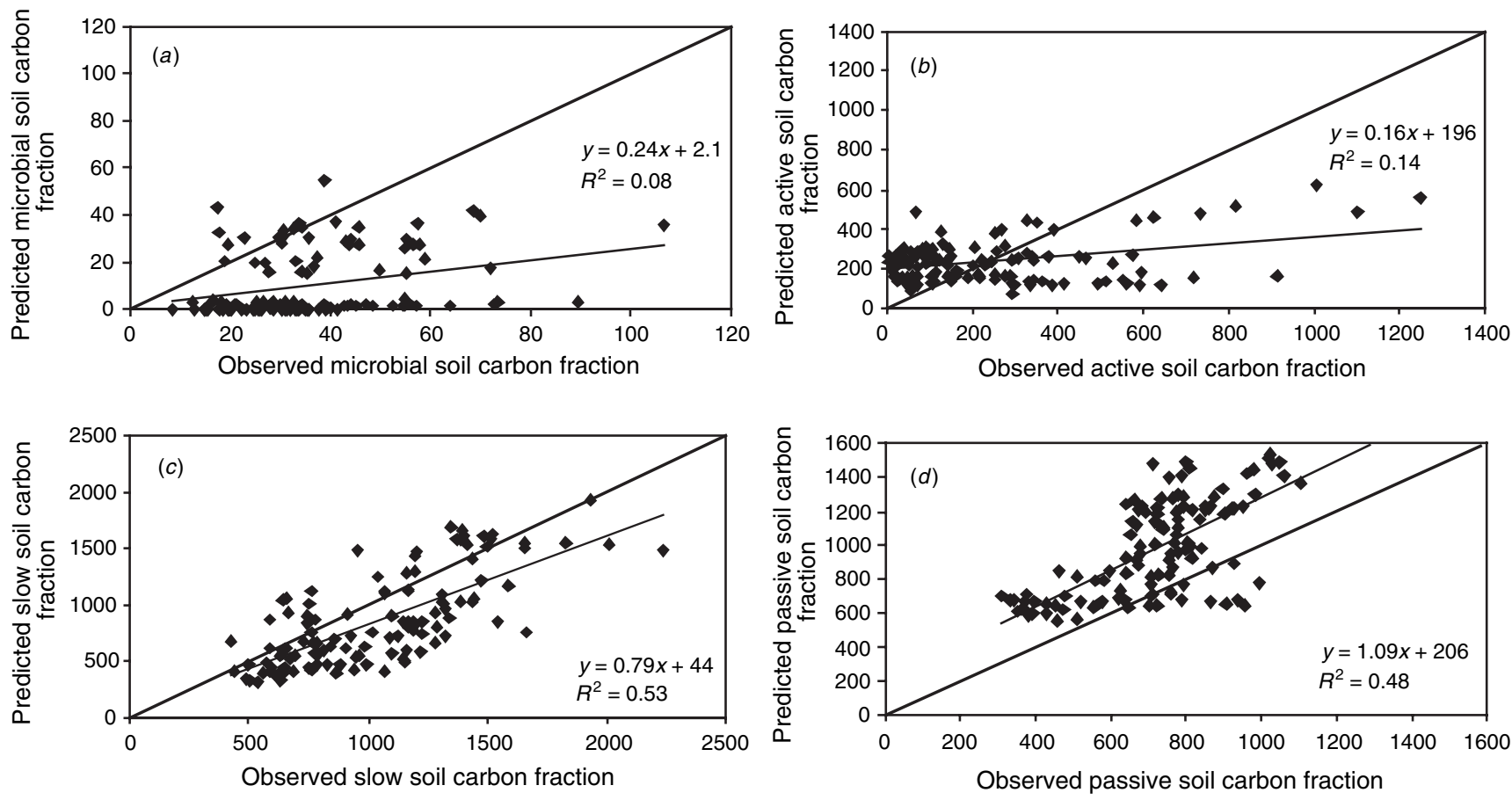

Fig. 5. Observed $v$. predicted carbon pool distribution for all sites and all ages of cultivation: $(a)$ microbial pool, $(b)$ active pool, $(c)$ slow pool, and $(d)$ passive pool. The solid line is the $1: 1$ line, with other line the linear regression.

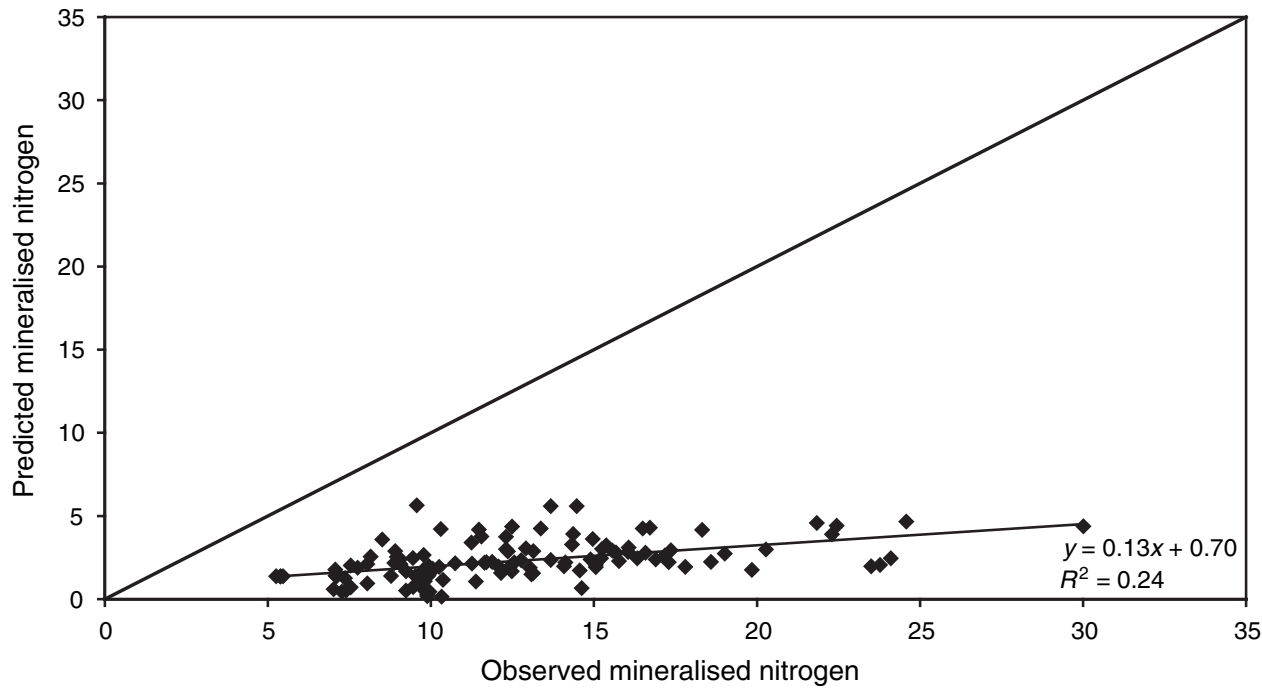

Fig. 6. Observed $v$. predicted mineralised nitrogen ( $\mathrm{kg} / \mathrm{ha}, 0-0.20 \mathrm{~m}$ depth) for all sites and all ages of cultivation. The solid diagonal line is the $1: 1$ line, with other line the linear regression.

model would substantially overestimate the SOM content and underestimate the SOM losses from cultivation.

Given the inherent site variability, and that all replicates had the same pre-clearing land-use schedule, it is surprising how well the model met the initial conditions. The accuracy of the model in predicting the pre-clearing and cultivation effects on SOM can be attributed to the level of site-specific information available. Each replicate had separate measures of soil texture, bulk density, and climate records. The accuracy in the estimates of the initial condition could be attributed to having reasonable estimates of the $\mathrm{C}$ inputs of the native vegetation and the simulated burning regime. Across the replicates, the simulation of the trends over time of soil $\mathrm{C}$ yielded significant relationships $(P<0.01)$, explaining most of the variation in the data. The model was most successful at Riverview, the site with the lowest clay content and no shrink-swell characteristics. 


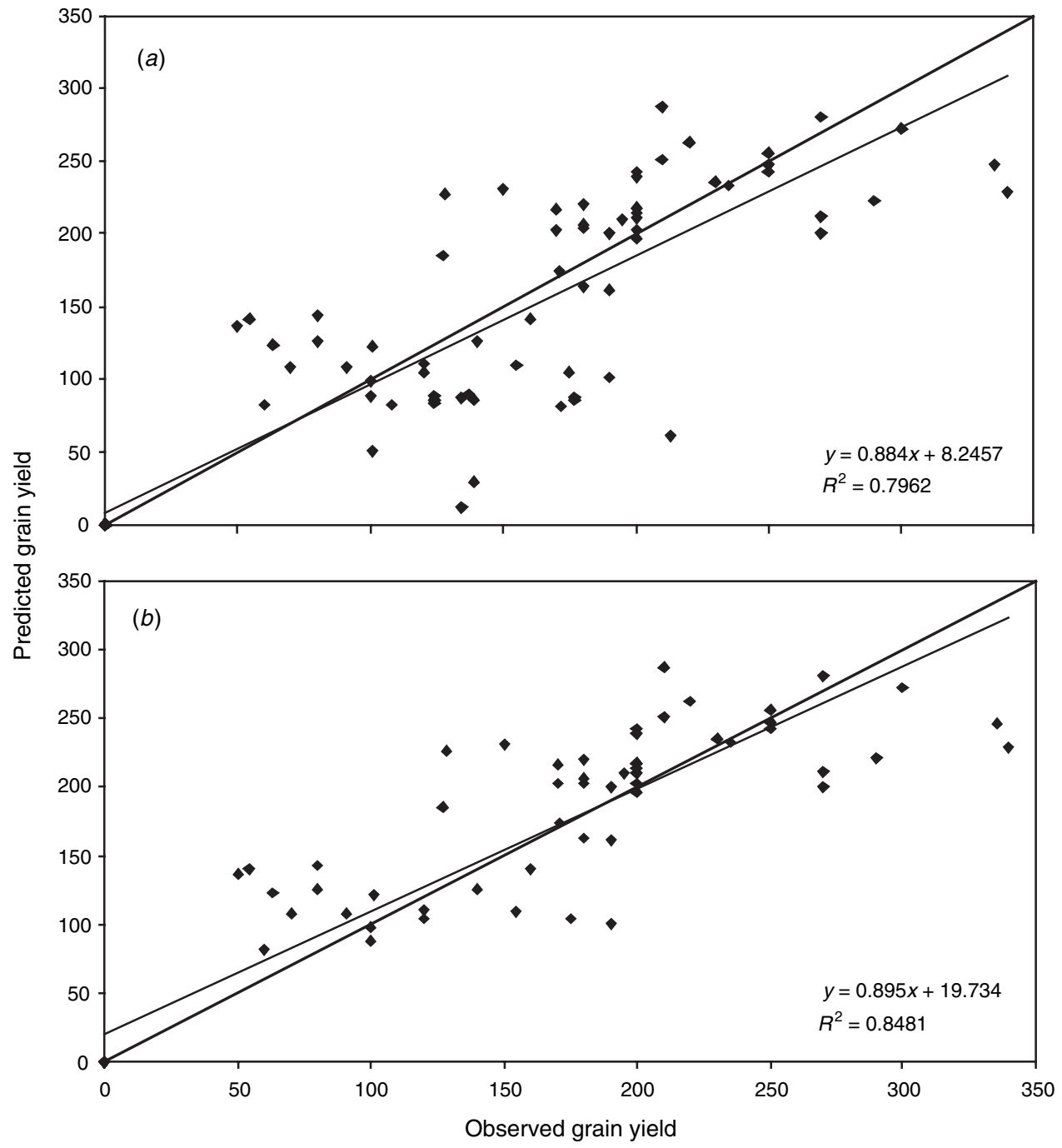

Fig. 7. Observed $v$. predicted grain yield ( $\mathrm{kg} /$ ha.year) for $(a)$ all sites and ages of cultivation, and $(b)$ with Thallon removed. The solid line is the $1: 1$ line, with other line the linear regression.

The ability of the CENTURY model to predict the carbon pool fractions varied, underestimating the rapid turnover pools (active and microbial), poorly estimating the passive pool at all but one site, but having reasonable success with the slow pool at all sites. Many of these problems may stem from a misfit between the classification of the observational data and the conceptual carbon fractions in the model. For example, the CENTURY model did not show the reductions in the active pool (rather limiting the size of the pool) following cultivation, or follow the trend in the observed data that showed a reduction in this pool. In this instance, we compared the sand $(>20 \mu \mathrm{m})$ fraction to a combination of the SOM1C(2) + Strucc (2) + Metabc (2), clearly with limited success (data not shown).

There have been few attempts to compare the different carbon pools against experimentally determined pools of SOM, and this study demonstrates distinct differences between the observed pools and the conceptual pools defined in the model.
Motavalli et al. (1994) used the CENTURY model to estimate soil carbon pools in tropical forest soils of varying clay contents and clay mineralogies. They concluded that, besides soil texture and mineralogy, other factors may have as much, or greater, influence on SOC stabilisation, and hence equilibrium SOC levels in these soils. Arrouays et al. (1985) believed that spatial variability of SOM must also be considered. Cook et al. (1992) observed that erosion was common on the soils in the study area under traditional cultivation, and this may account for many of the changes of soil properties. The version of the CENTURY model used in these simulations did not account for runoff and soil losses caused by erosion, and this may have had the greatest effect on the most rapid turnover pools. The lack of predictability for the passive fraction at some sites may relate to carbon chemistry, and other chemical methods for determining this fraction need considering. Historical fires are likely to have added a significant amount of charcoal to 
those sites with high grassland productivity. The version of CENTURY does not simulate charcoal, and Skjemstad et al. (1999) showed that the Waco soil can contain up to $30 \%$ char $\mathrm{C}$, while soil from the densely wooded site contained about $4 \%$ charcoal $\mathrm{C}$.

In this study we also compared the observed and predicted grain yields to test whether there was a reasonable prediction of grain yields, and the model maintained a sensible steady-state return of $\mathrm{C}$ to the soil. At most sites, the CENTURY model made good predictions of grain yield, with the exception of Thallon. The Thallon site had the lowest observed total SOC and would be expected to have the lowest crop yields, but this was not the case. It is difficult to assess why the model performed poorly at this site, and it was also not possible to check the validity of the observed data at this site (although it was at all other sites), and this may explain the inconsistencies between the observed and predicted values. Also, given the changes in the wheat varieties that were noted in the site records, the use of break crops and summer crops such as sorghum, and the fact that the site notes and records were not complete for the other cropping activities, thus not allowing them to be fully reflected in the model schedules, the CENTURY model satisfactorily predicted the wheat yields and the impacts on the SOC totals and pools except for the Thallon soil series sites (Fig. 7).

\section{Conclusions}

The ability of the CENTURY model to closely predict the impact of continuous cultivation and cereal cropping suggests the possibility of utilising the model to test the effects of changing cultivation and fertiliser practice on soil carbon content, and ultimately to evaluate the sustainability of changed practice. The strength of the model lies in its ability to predict the starting SOM condition (before the imposition of treatments), and as an empirical model being able to accurately predict the impacts of clearing native vegetation, cultivation, fertiliser application, and continuous cropping on total soil carbon. Given the fundamental importance of soil carbon in maintaining soil health and productive potential, the CENTURY model provides an opportunity to test the long-term organic matter status and sustainability of cropping and cultivation in southern Queensland.

\section{References}

Arrouays D, Vion I, Kicin JL (1985) Spatial analysis and modelling of topsoil carbon storage in temperate forest humic loamy soils of France. Soil Science 150, 191-198.

Carter MR, Parton WJ, Rowland IC, Schulz JE, Steed GR (1993) Simulation of soil organic carbon and nitrogen changes in cereal and pasture systems of Southern Australia. Australian Journal of Soil Research 31, 481-491. doi: 10.1071 SR9930481

Cook GD, So HB, Dalal RC (1992) Structural degradation of two Vertosols under continuous cultivation. Soil and Tillage Research 24, 47-64. doi: 10.1016/0167-1987(92)90071-I

Dalal RC, Mayer RJ (1986a) Long-term trends in fertility of soil under continuous cultivation and cereal cropping in southern Queensland. I. Overall changes in soil properties and trends in winter cereal yields. Australian Journal of Soil Research 24, 265-279. doi: $10.1071 /$ SR9860265
Dalal RC, Mayer RJ (1986b) Long-term trends in fertility of soil under continuous cultivation and cereal cropping in southern Queensland. II. Total organic carbon and its rate of loss from the soil profile. Australian Journal of Soil Research 24, 281-292. doi: 10.1071/SR9860281

Dalal RC, Mayer RJ (1986c) Long-term trends in fertility of soil under continuous cultivation and cereal cropping in southern Queensland. III. Distribution and kinetics of soil organic carbon in particlesize fractions. Australian Journal of Soil Research 24, 265-279. doi: 10.1071/SR9860265

Dalal RC, Mayer RJ (1986d) Long-term trends in fertility of soil under continuous cultivation and cereal cropping in southern Queensland. IV. Loss of organic carbon from density functions. Australian Journal of Soil Research 24, 301-309. doi: 10.1071/SR9860301

Dalal RC, Mayer RJ (1986e) Long-term trends in fertility of soil under continuous cultivation and cereal cropping in southern Queensland. $\mathrm{V}$. Rate of loss of total nitrogen from the soil profile and changes in carbon: nitrogen ratios. Australian Journal of Soil Research 24, 493-504. doi: 10.1071/SR9860493

Dalal RC, Mayer RJ (1987a) Long-term trends in fertility of soil under continuous cultivation and cereal cropping in southern Queensland. VI. Loss of total nitrogen from different particle-size and density fractions. Australian Journal of Soil Research 25, 83-93. doi: $10.1071 /$ SR9870083

Dalal RC, Mayer RJ (1987b) Long-term trends in fertility of soil under continuous cultivation and cereal cropping in southern Queensland. VII. Dynamics of nitrogen mineralization potentials and microbial biomass. Australian Journal of Soil Research 25, 461-472. doi: 10.1071/SR9870461

Dalal RC, Mayer RJ (1990) Long-term trends in fertility of soil under continuous cultivation and cereal cropping in southern Queensland. VIII. Available nitrogen indices and their relationship to crop yield and N uptake. Australian Journal of Soil Research 28, 563-575. doi: 10.1071/SR9900563

Day KA, McKeon GM, Carter JO (1997) Evaluating the risk of pasture and land degradation in native pastures in Queensland. Final Report for the RIRDC project DAQ124A, Brisbane.

Harrington GN (1979) Estimation of above-ground biomass of trees and shrubs in a Eucalyptus populnea F. Muell. woodland by regression of mass on trunk diameter and plant height. Australian Journal of Botany 27, 135-143. doi: 10.1071/BT9790135

Holland EA, Parton WJ, Detling JK, Coppock DL (1992) Physiological responses of plant populations to herbivory and their consequences for ecosystem nutrient flows. American Naturalist 140, 685-706. doi: $10.1086 / 285435$

Jeffrey SJ, Carter JO, Moodie KB, Beswick AR (2001) Using spatial interpolation to construct a comprehensive archive of Australian climate data. Environmental Modelling \& Software 16, 309-330. doi: 10.1016/S1364-8152(01)00008-1

Judd TS, Attiwill PM, Adams MA (1996) Nutrient concentrations in Eucalyptus: A synthesis in relation to differences between taxa, sites and components. In 'Nutrition of eucalypts'. (Eds PM Attiwill, MA Adams) pp. 123-153. (CSIRO Publishing: Collingwood, Vic.)

Littleboy M, Silburn DM, Freebairn DM, Woodruff DR, Hammer GL (1989) PERFECT - A computer simulation model of productivity erosion runoff functions to evaluate conservation techniques. Queensland Department of Primary Industries Bulletin QB89005, Brisbane.

Metherell AK, Harding LA, Cole CV, Parton WJ (1993) CENTURY soil organic matter model environment, Technical documentation, Agroecosystem version 4.0. Great Plains Systems Research Unit Technical Report No. 4, Fort Collins, CO.

Moore AW, Russell JS, Coaldrake JE (1967) Dry matter and nutrient content of a subtropical semiarid forest of Acacia harpophylla F. Muell. (Brigalow). Australian Journal of Botany 15, 11-24. doi: 10.1071/BT9670011 
Motavalli PP, Palm CA, Parton WJ, Elliott ET, Frey SD (1994) Comparison of laboratory and modelling simulation methods for estimating soil carbon pools in tropical forest soils. Soil Biology \& Biochemistry 26, 935-944. doi: 10.1016/0038-0717(94)90106-6

Parton WJ, McKeown B, Kirchner V, Ojima DS (1992) CENTURY Users Manual. Colorado State University NREL Publication, Fort Collins, CO.

Parton WJ, Sanford RL, Sanchez PA, Stewart JWB (1989) Modeling soil organic matter dynamics in tropical soils. In 'Dynamics of soil organic matter in tropical ecosystems'. (Eds DC Coleman, JM Oades, G Uehara) pp. 153-171. (University of Hawaii Press: Honolulu)

Parton WJ, Schimel DS, Cole CV, Ojima DS (1987) Analysis of factors controlling soil organic matter levels in Great Plains grasslands. Soil Science Society of America Journal 51, 1173-1179.

Parton WJ, Schimel DS, Ojima DS, Cole CV (1994a) A general model for soil organic matter dynamics: sensitivity to litter chemistry, texture and management. In 'Quantitative modeling of soil farming processes'. (Eds RB Bryant, RW Arnold) pp. 147-167. (ASA, CSSA, SSA: Madison, WI)

Parton WJ, Woomer PL, Martin A (1994b) Modelling soil organic matter dynamics and plant productivity in tropical ecosystems. In 'The biological management of tropical soil fertility'. (Eds PL Woomer, MJ Swift) pp. 171-188. (John Wiley \& Sons: Chichester, UK)

Paustian K, Parton WJ, Persson J (1992) Modeling soil organic matter in organic amended and nitrogen-fertilised long-term plots. Soil Science Society of America Journal 56, 476-488.
Sanford RL Jr, Parton WJ, Ojima DS, Lodge DJ (1991) Hurricane effects on soil organic matter dynamics and forest production in the Luquillo Experimental Forest, Puerto Rico: results of simulation modelling. Biotropica 23, 364-372. doi: 10.2307/2388253

Skjemstad JO, Taylor JA, Smernik RJ (1999) Estimation of charcoal (char) in soils. Communications in Soil Science and Plant Analysis 30, 2283-2298.

Smith P, Smith JU, Powlson DS, McGill WB, Chertov OG, Coleman K, Franko U, Frolking S, Jenkinson DS, Jensen LS, Kelly RH, Klein-Gunnewiek H, Komarov AS, Li C, Molina JAE, Mueller T, Parton WJ, Thornley JHM, Whitmore AP (1997) A comparison of the performance of nine soil organic matter models using datasets from seven long-term experiments. Geoderma 81, 153-225. doi: 10.1016/S00167061(97)00087-6

Woomer PL (1993) The impact of cultivation on carbon fluxes in woody savannas of Southern Africa. Water, Air, and Soil Pollution 70, 403-421. doi: $10.1007 / \mathrm{BF} 01105011$

Manuscript received 8 August 2006, accepted 22 March 2007 